\title{
Bioinformatics analysis of the transcriptional expression of minichromosome maintenance proteins as potential indicators of survival in patients with cervical cancer
}

\author{
Baojie $W^{*}$ and Shuyi $X i$
}

\begin{abstract}
Background: As major regulators of DNA replication in eukaryotes, minichromosome maintenance (MCM) proteins play an important role in the initiation and extension of DNA replication. MCMs and their related genes may be new markers of cell proliferation activity, which is of great significance for the diagnosis and prognosis of cervical cancer.

Methods: To explore the role of MCMs and their related genes in cervical cancer, various bioinformatics methods were performed. First, the ONCOMINE and UALCAN databases were used to analyze the mRNA expression of different MCMs. The Human Protein Atlas database was used to analyze the protein expression of MCMs in normal and tumor tissues. The potential clinical value of MCMs was evaluated using the UALCAN, Kaplan-Meier plotter and cBioPortal databases. Then, the related genes and key coexpressed genes of MCMs were screened using GEPIA2 and cBioPortal analysis. For these genes, we used Metascape and the DAVID database to perform Gene Ontology (GO) and Kyoto Encyclopedia of Genes and Genomes (KEGG) pathway enrichment analyses, construct the related molecular interaction network, and obtain the key subnetworks and related hub genes. The Kaplan-Meier plotter database was used for survival analysis of cervical cancer patients to evaluate and predict the potential clinical value of the hub genes. Moreover, multiple gene comparisons of the expression of MCMs and related genes in different cancer types also showed the clinical significance of these potential targets.
\end{abstract}

* Correspondence: w3522021987@163.com

Shanghai Zerun Biotechnology Co., Ltd., Pilot Department, Building 9, 1690

Zhangheng Road Pudong, Shanghai 201203, China

C C The Author(s). 2021 Open Access This article is licensed under a Creative Commons Attribution 4.0 International License, which permits use, sharing, adaptation, distribution and reproduction in any medium or format, as long as you give appropriate credit to the original author(s) and the source, provide a link to the Creative Commons licence, and indicate if changes were made. The images or other third party material in this article are included in the article's Creative Commons licence, unless indicated otherwise in a credit line to the material. If material is not included in the article's Creative Commons licence and your intended use is not permitted by statutory regulation or exceeds the permitted use, you will need to obtain permission directly from the copyright holder. To view a copy of this licence, visit http://creativecommons.org/licenses/by/4.0/. The Creative Commons Public Domain Dedication waiver (http://creativecommons.org/publicdomain/zero/1.0/) applies to the data made available in this article, unless otherwise stated in a credit line to the data. 
Results: The mRNA and protein expression of MCMs increased in tumor tissue. Overexpression of MCM2/3/4/5/6/7/ $8 / 10$ was found to be significantly associated with clinical cancer stage. Higher mRNA expression levels of MCM3/5/ 6/7/8 were found to be significantly associated with longer overall survival, and higher mRNA expression of MCM2/ 3/4/5/6/7/8 was associated with favorable OS. In addition, a high mutation rate of MCMs (71\%) was observed. MCM2, MCM4, MCM8, MCM3 and MCM7 were the five genes with the most genetic alterations. In addition, the coexpressed genes and related genes of MCMs were successfully screened for enrichment analysis. These genes were significantly enriched in important pathways, such as the DNA replication, cell cycle, mismatch repair, spliceosome, and Fanconi anemia pathways. A protein-protein interaction network was successfully constructed, and a total of 13 hub genes (CDC45, ORC1, RPA1, CDT1, TARDBP, RBMX, SRSF3, SRSF1, RFC5, RFC2, MSH6, DTL, and MSH2) from 4 key subnetworks were obtained. These genes and MCM2/3/4/5/6/7/8 might have potential clinical value for the survival and prognosis of cervical cancer patients.

Conclusions: These findings promoted the understanding of the MCM protein family and clinically related molecular targets for cervical epithelial neoplasia and cervical cancer. Our results were helpful to evaluate the potential clinical value of MCMs and related genes in patients with cervical cancer.

Keywords: Minichromosome maintenance proteins, Transcriptional expression, Cervical intraepithelial neoplasia, Cervical cancer, Functional enrichment, Survival and prognosis

\section{Background}

The minichromosome maintenance $(\mathrm{MCM})$ protein family is a group of proteins closely related to DNA replication and genome stability [1]. Highly conserved MCM complex proteins may have helicase activity and are essential for the initiation of DNA replication. MCM complex proteins contain ATPase domains, and energy is harnessed to affect DNA unwinding [2]. There are ten characterized homologous MCM genes. MCM2-7 form a replicative helicase complex [3], and MCM8 and MCM9 form a dimer involved in homologous recombination repair [4]. The ninth gene that encodes an MCM domain is named MCM domain-containing 2 (MCMD C2) [5]. MCM10 is a dynamic scaffold at eukaryotic replication forks [6].

It has been reported that the expression of MCMs in the cell proliferation cycle is one of the important factors of DNA replication initiation and extension, and their positive expression is an important marker of cell proliferation [7]. Their expression levels are related to the proliferation and differentiation of tumor cells and can accurately reflect the proliferation activity of cells. MCMs have great reference value in the early diagnosis, classification and prognosis of clinical tumors [8,9]. Therefore, it is necessary to strengthen the research on the basic theory and clinical application value of MCMs, including their mechanism of protein action, their expression characteristics and their related genes in cervical cancer tissue, as well as their value in clinical diagnosis and differential diagnosis. At present, there are few related studies in these areas. In this study, the roles of MCMs and related genes in cervical cancer were investigated by a variety of bioinformatics methods. By analyzing the mRNA and protein expression of MCM family members, their potential clinical value in cervical cancer was analyzed. The workflow of this study is shown in Fig. 1.

\section{Methods}

Expression of different MCMs in cervical cancer patients To explore the distinct prognostic and potential therapeutic values of different MCM members in cervical cancer patients, the mRNA expression of different MCMs was analyzed by the ONCOMINE database [10] (www.oncomine. org) and UALCAN [11] (http://ualcan. path.uab.edu). After analyzing the mRNA expression, the protein expression of different MCMs in cervical cancer was explored by the Human Protein Atlas [1214] (HPA, http://www.proteinatlas.org) database, and the results of immunohistochemistry from HPA showed the expression of MCMs in normal tissues and tumor tissues. The data used for analysis were from databases, and the expression results of different MCMs can provide a reference for evaluating their potential clinical value.

\section{Potential clinical value of MCMs}

After mRNA and protein expression analyses, the relationship between the mRNA expression of MCMs and the clinicopathological parameters of patients, such as individual cancer stages, was assessed by performing The Cancer Genome Atlas (TCGA) database analysis via UALCAN. The data used for analysis were from the database, and the analysis results showed the potential value of different MCMs in clinical pathology. Moreover, the survival of patients was analyzed, and specific MCMs related to better prognosis were identified. 


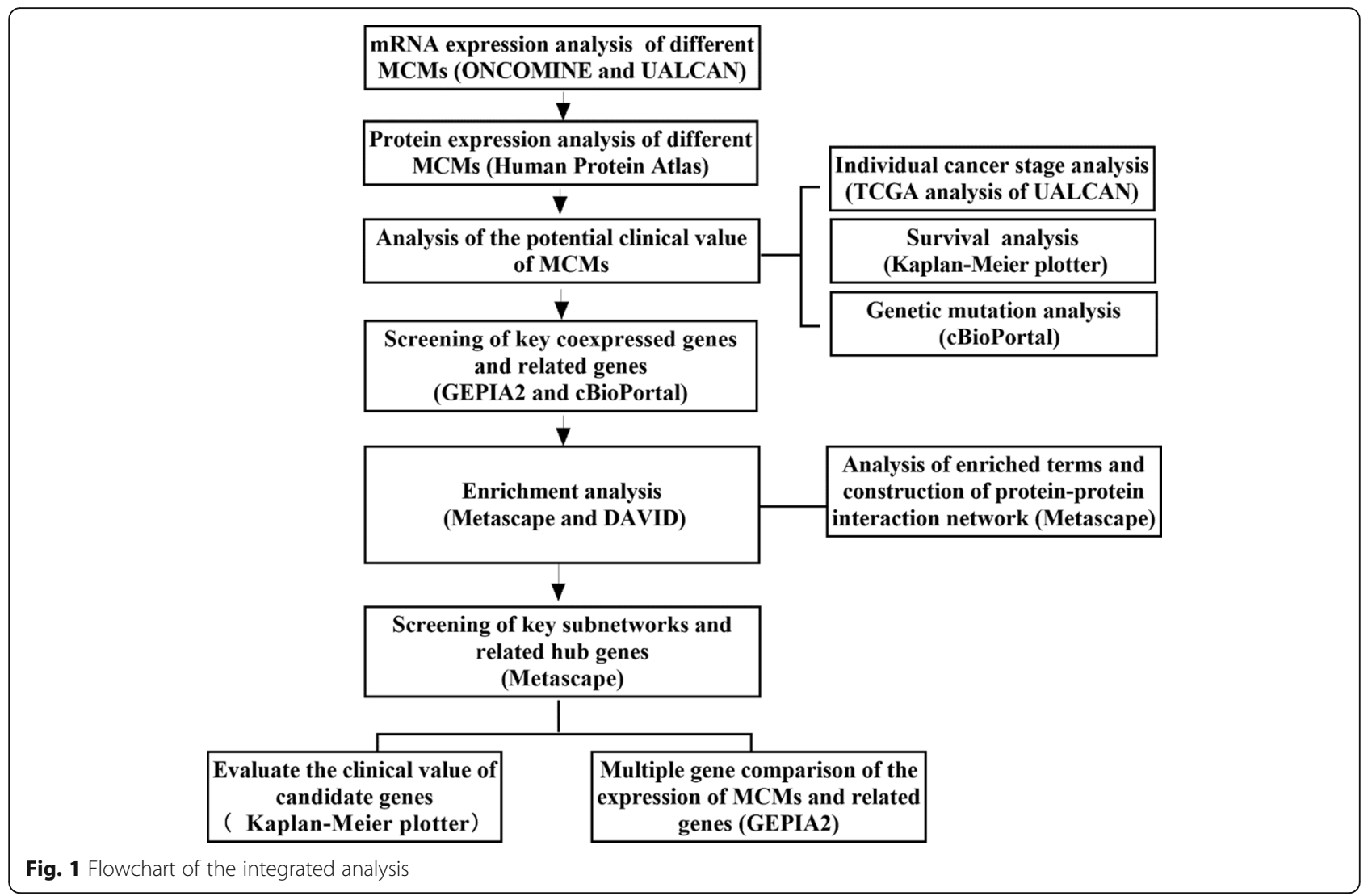

Furthermore, the Kaplan-Meier plotter database [15, 16] (http://kmplot.com/analysis/) was used to analyze the prognostic value of the mRNA expression of different MCMs in cancer patients. The correlation between the mRNA expression of MCMs and the prognosis of patients with cervical cancer was explored and analysed. MCMs useful for predicting the survival of patients with cervical cancer were identified.

After mRNA expression of specific MCMs was found to be significantly associated with patient prognosis, genetic alterations in MCMs and their associations with overall survival (OS) and disease-free survival (DFS) of cervical squamous cell carcinoma (CESC) patients were analyzed by the cBioPortal database $[17,18]$ (www.cbioportal.org). Analysis of genetic alterations promoted the exploration and understanding of different MCMs in CESC, identified MCMs that are prone to alteration and provided information support for genetic alterations of MCMs in cervical cancer. In addition, key coexpressed genes of MCMs in CESC (TCGA, PanCancer Atlas) were screened and analyzed via a Venn diagram (http:// bioinformatics.psb.ugent.be/webtools/Venn/).
Similar gene detection and enrichment analysis of related genes in CESC tumors

After the analysis of the ONCOMINE, UALCAN, HPA, Kaplan-Meier plotter and cBioPortal databases, the functions of the MCMs with potential value and their related genes in CESC tumors were further enriched and explored. Genes that had a similar expression pattern to MCMs in CESC tumors were analyzed by GEPIA2 [19] (http://gepia2.cancer-pku.cn/\#similar). Then, the key coexpressed genes and related genes of MCMs in CESC tumors were analyzed by Metascape [20] (https:// metascape.org/gp/index.html). The pathways and process enrichment of these genes were determined [21]. Database for Annotation, Visualization and Integrated Discovery (DAVID, https://david.ncifcrf.gov/) was also used to verify the biological processes, cellular components, molecular functions and KEGG pathways of these genes [22-24].

Protein-protein interaction (PPI) network construction and screening of hub genes

Next, the network of enriched terms and the PPI network were also analyzed by Metascape [25-27]. Then, key subnetworks and related hub genes were 
obtained, and the Kaplan-Meier plotter database was used for survival analysis of cervical cancer patients to evaluate and predict the potential clinical value of the hub genes [28]. Moreover, multiple gene comparisons of the expression of MCMs and related genes in different cancer types were performed to show the clinical significance of these potential targets by GEPI A2. In particular, MCMs and their related genes that are involved in the progression of cervical cancer might provide potential targets for the clinical prevention, treatment, and effective prognostication of cervical cancer.

\section{Results}

Expression of different MCMs in cervical cancer patients As shown in Fig. 2 and Table 1, the mRNA expression levels of MCM2/3/4/5/6/7/8/9/10 in cervical cancer tissues and normal tissues were compared using the
ONCOMINE database [29-32], and MCM2/3/4/5/6/7/ $8 / 10$ expression was significantly increased in tumor tissues. Then, the mRNA expression of MCM2/3/4/5/6/7/ $8 / 9 / 10$ was further analyzed by the UALCAN database. As shown in Fig. 3, the mRNA expression of MCM2/3/ $4 / 5 / 6 / 7 / 8 / 10$ in tumor tissues was significantly higher than that in normal tissues $(p<0.05)$, while the expression of MCM8/9/10 in tumor tissues was lower than that of other MCMs (MCM2/3/4/5/6/7). However, the expression of MCM9 in tumor tissues was not significant. In addition to the above analysis, immunohistochemical information was obtained from the HPA database to analyze the protein expression of MCMs in normal and tumor tissues (Fig. 4). MCM2 and MCM5 were not detected in normal tissues, but their high expression was observed in tumor tissues. The expression of MCM6/9/10 was low in normal tissues, but medium and high protein expression was observed in tumor
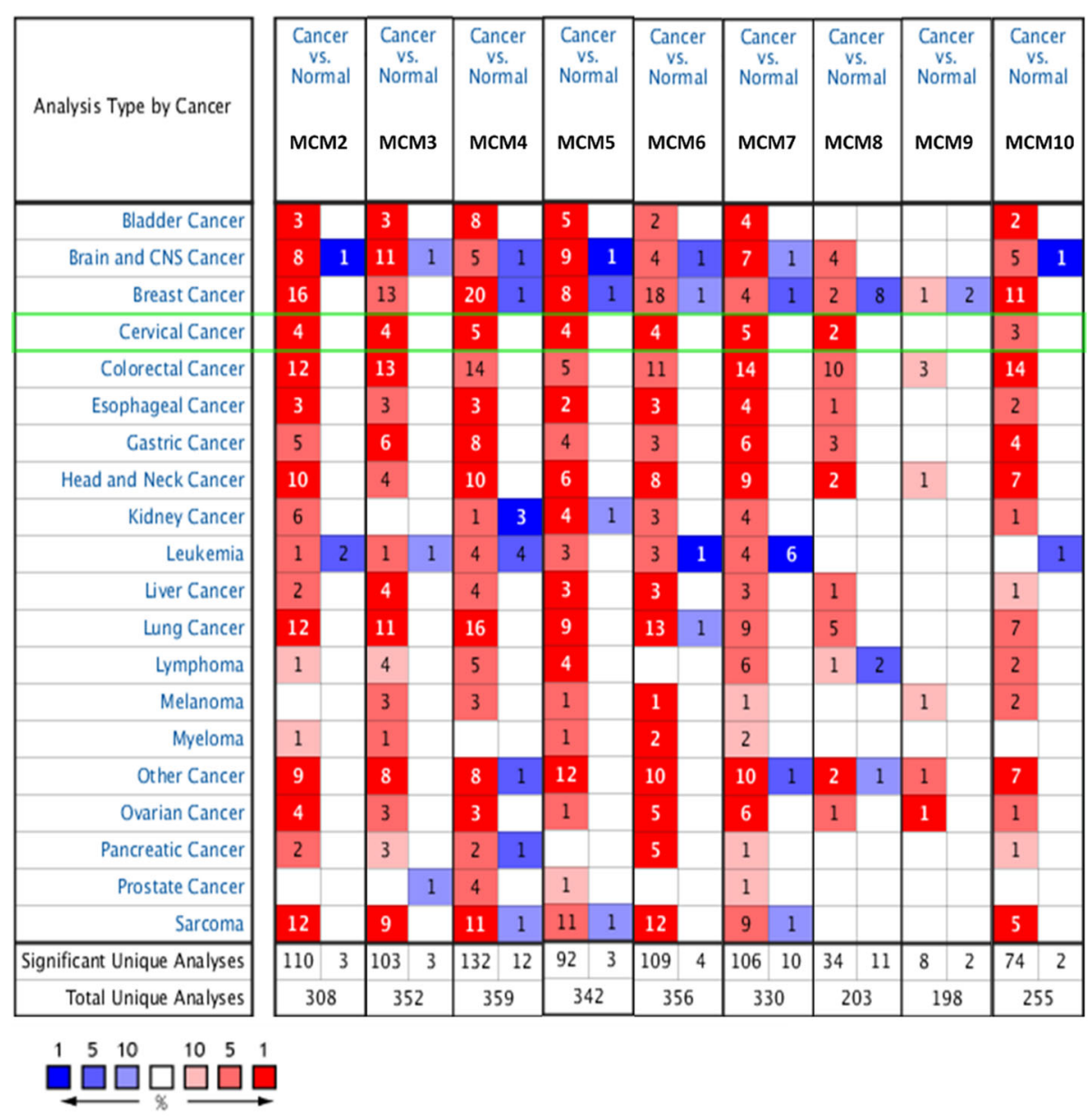

Cell color is determined by the best gene rank percentile for the analyses within the cell.

NOTE: An analysis may be counted in more than one cancer type.

Fig. 2 Transcriptional expression of MCMs in different types of cancer (ONCOMINE). Differences in transcriptional expression were compared by ttests. The cutoff $p$-value, fold change, and other settings were as follows: $p$-value: 0.01 , fold change: 1.5 , gene rank: top 10\%, data type: mRNA 
Table 1 Significant changes in MCM expression at the transcription level between cervical cancer tumor and normal tissues (ONCOMINE)

\begin{tabular}{|c|c|c|c|c|c|}
\hline MCMs & Types & Fold Change & $P$-value & T-test & References \\
\hline \multirow[t]{4}{*}{$\overline{\mathrm{MCM} 2}$} & CESC & 5.984 & $2.3 \mathrm{E}-17$ & 12.158 & Scotto Cervix 2 [29] \\
\hline & CESCE & 5.714 & $3.12 \mathrm{E}-13$ & 13.368 & Zhai Cervix [30] \\
\hline & CC & 5.219 & $3.28 \mathrm{E}-14$ & 11.233 & Pyeon Multicancer [31] \\
\hline & CESC & 2.76 & $1.00 \mathrm{E}-05$ & 11.995 & Biewenga Cervix [32] \\
\hline \multirow[t]{4}{*}{ MCM3 } & CC & 4.18 & $2.84 \mathrm{E}-13$ & 11.188 & Pyeon Multicancer [31] \\
\hline & CESC & 2.613 & $1.05 \mathrm{E}-10$ & 7.947 & Scotto Cervix 2 [29] \\
\hline & CESCE & 1.73 & $2.44 \mathrm{E}-07$ & 7.464 & Zhai Cervix [30] \\
\hline & CESC & 2.589 & $1.48 \mathrm{E}-06$ & 12.088 & Biewenga Cervix [32] \\
\hline \multirow[t]{5}{*}{ MCM4 } & CESCE & 2.100 & $3.03 \mathrm{E}-11$ & 10.279 & Zhai Cervix [30] \\
\hline & $\mathrm{HG}-\mathrm{CIN}$ & 2.161 & 0.001 & 3.672 & Zhai Cervix [30] \\
\hline & CC & 4.103 & $1.48 \mathrm{E}-13$ & 11.000 & Pyeon Multicancer [31] \\
\hline & CESC & 3.175 & $3.90 \mathrm{E}-10$ & 7.686 & Scotto Cervix 2 [29] \\
\hline & CESC & 2.806 & $6.06 \mathrm{E}-06$ & 12.289 & Biewenga Cervix [32] \\
\hline \multirow[t]{4}{*}{ MCM5 } & CESC & 4.399 & $3.80 \mathrm{E}-14$ & 10.142 & Scotto Cervix 2 [29] \\
\hline & CC & 3.623 & $3.49 \mathrm{E}-11$ & 9.255 & Pyeon Multicancer [31] \\
\hline & CESCE & 9.905 & $1.59 \mathrm{E}-05$ & 7.196 & Zhai Cervix [30] \\
\hline & CESC & 2.550 & 7.54E-06 & 13.686 & Biewenga Cervix [32] \\
\hline \multirow[t]{4}{*}{ MCM6 } & CESC & 3.731 & $6.25 \mathrm{E}-13$ & 9.510 & Scotto Cervix 2 [29] \\
\hline & CC & 4.004 & $3.28 \mathrm{E}-12$ & 10.400 & Pyeon Multicancer [31] \\
\hline & CESCE & 2.655 & $2.93 \mathrm{E}-07$ & 8.894 & Zhai Cervix [30] \\
\hline & CESC & 3.130 & $1.03 \mathrm{E}-07$ & 17.000 & Biewenga Cervix [32] \\
\hline \multirow[t]{5}{*}{ MCM7 } & CESC & 3.728 & $5.77 \mathrm{E}-11$ & 8.050 & Scotto Cervix 2 [29] \\
\hline & CESCE & 3.233 & $5.10 \mathrm{E}-07$ & 8.604 & Zhai Cervix [30] \\
\hline & $\mathrm{HG}-\mathrm{CIN}$ & 2.480 & 0.003 & 3.577 & Zhai Cervix [30] \\
\hline & $\mathrm{CC}$ & 2.768 & 2.90E-09 & 7.790 & Pyeon Multicancer [31] \\
\hline & CESC & 2.666 & $1.54 \mathrm{E}-07$ & 13.539 & Biewenga Cervix [32] \\
\hline \multirow[t]{2}{*}{ MCM8 } & $\mathrm{CC}$ & 4.454 & $3.82 \mathrm{E}-14$ & 11.480 & Pyeon Multicancer [31] \\
\hline & CESC & 1.907 & 0.00000942 & 11.006 & Biewenga Cervix [32] \\
\hline MCM9 & & & & & Need further study \\
\hline \multirow[t]{3}{*}{ MCM10 } & CESCE & 2.287 & 0.00000367 & 5.779 & Zhai Cervix [30] \\
\hline & CESC & 4.046 & $1.47 \mathrm{E}-06$ & 5.463 & Scotto Cervix 2 [29] \\
\hline & $\mathrm{CC}$ & 2.176 & $2.74 \mathrm{E}-08$ & 7.154 & Pyeon Multicancer [31] \\
\hline
\end{tabular}

Cervical squamous cell carcinoma epithelia: CESCE; High-grade cervical squamous intraepithelial neoplasia epithelia: HG-CIN; Cervical cancer: CC; Cervical squamous cell carcinoma: CESC

tissues. In addition, medium protein expression of MCM3/4/7 was observed in normal tissues, and high protein expression was observed in tumor tissues. Moreover, high expression of MCM2/3/5/7 was associated with good survival and prognosis (Fig. 5).

\section{Potential clinical value of MCMs and screening of coexpressed genes}

As shown in Fig. 6, the results showed that the mRNA expression of MCMs was significantly correlated with individual cancer stages in the UALCAN database, and cancer patients (stage 1-stage 4) had higher mRNA expression of MCMs than normal controls. The effects of MCM2 and MCM5 expression are shown in Fig. 7. High expression of MCM2 and MCM5 had a significant impact on patients, and they might be better targets to promote the good survival and prognosis of patients.

Furthermore, the prognostic value of the mRNA expression of MCMs was evaluated using the Kaplan- 


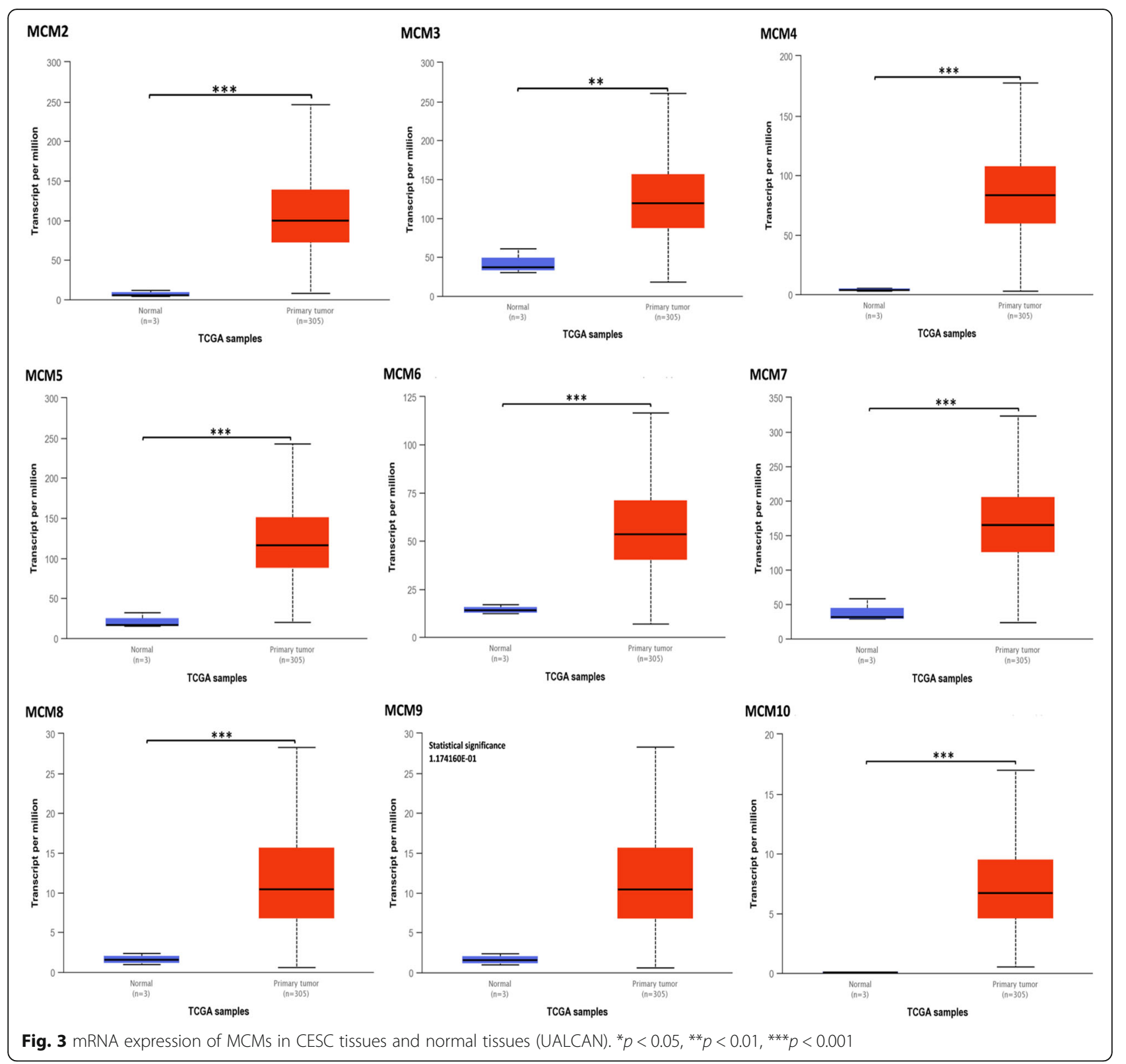

Meier plotter database (Fig. 8). The mRNA expression of MCM2/3/4/5/6/7/8 was significantly associated with CESC patient prognosis, and the results showed that higher mRNA expression of MCM2/3/4/5/6/7/8 was associated with favorable OS in CESC patients. Moreover, higher mRNA expression of MCM3/5/6/7/ 8 was significantly associated with longer OS, but the mRNA expression of MCM9, MCM10 and MCMDC2 had no significant effect on the prognosis of CESC patients (Fig. 9). These results indicated that MCM2/ $3 / 4 / 5 / 6 / 7 / 8$ may serve as useful biomarkers for CESC patients.

In particular, genetic mutations in MCMs and their associations with OS and DFS were explored by the
cBioPortal database. The cBioPortal analysis showed a high mutation rate $(71 \%)$ of MCMs in CESC patients (TCGA, PanCancer Atlas). MCM2, MCM4, MCM8, $M C M 3$ and $M C M 7$ were the top five genes with the highest genetic alterations, and the mutation rates were $35,20,19,15$ and 14\%, respectively (Fig. 10). Moreover, the results showed that genetic alterations in MCMs were not significantly associated with longer OS or DFS in CESC patients.

Furthermore, to deeply explore the potential clinical value of MCMs, their coexpressed genes were analyzed using the cBioPortal database. The coexpressed genes of $M C M 2 / 3 / 4 / 5 / 6 / 7 / 8$ (top 25 correlated genes) were screened, and the results of 


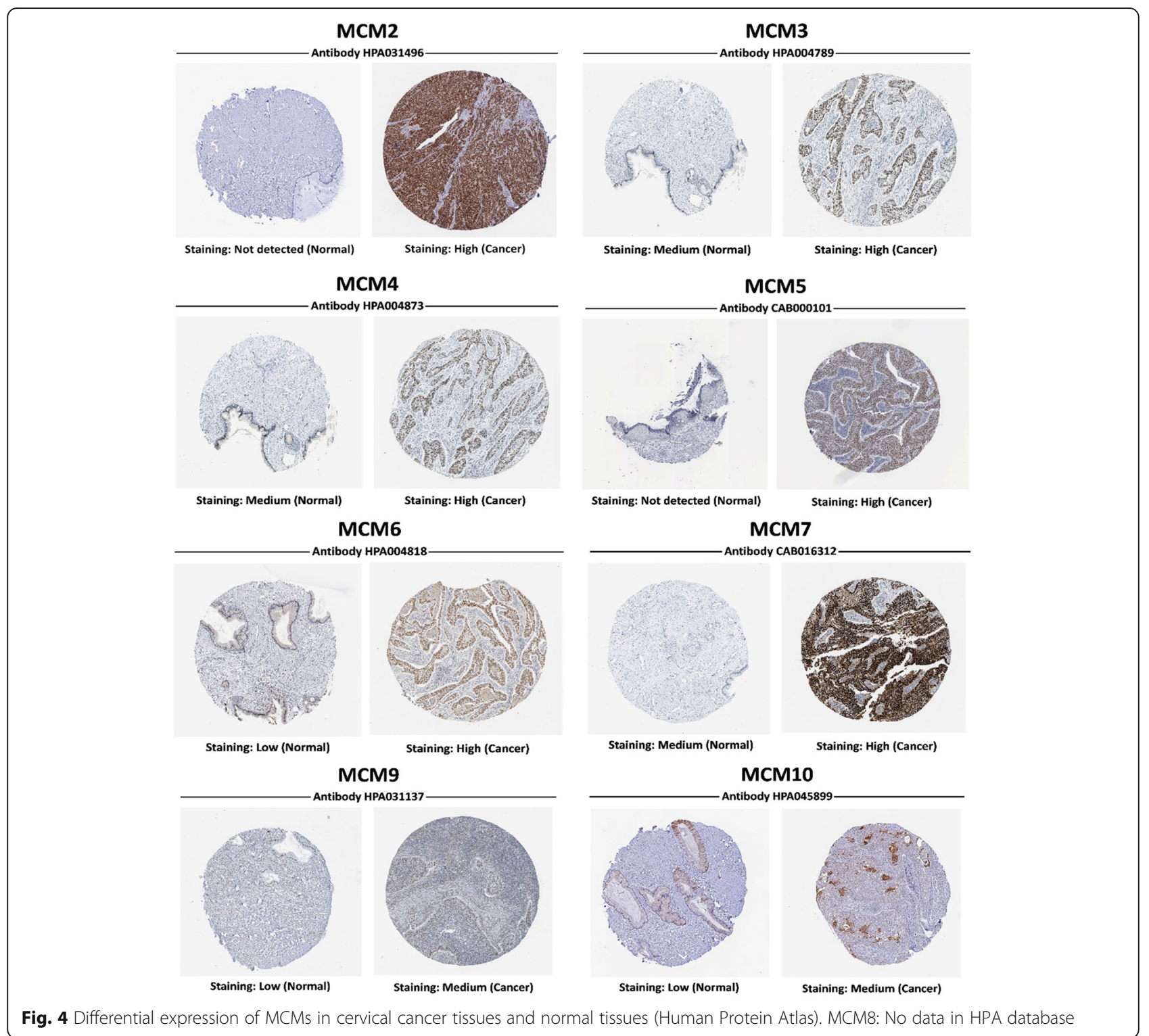

intersection analysis are shown in Table 2. A total of 9 intersections and 16 key coexpressed genes (MCM5 [33], CHAF1B, MCM2, GINS2, MCM6, RFC5, FANCC, TIMELESS, CLSPN, BRIP1, RBL1, $C D T 1, R F C 2, C D C 45, O R C 1$, and TOP2A) were obtained for further study.

\section{Detection and enrichment analysis of related genes}

Next, the top 50 genes related to MCMs were identified by GEPIA2. The 57 selected genes (as shown in Table 3) and $M C M 7 / 8$ were analyzed by Metascape. The pathway and process enrichment analysis results are shown in Fig. 11. The results showed that MCMs and related genes (59 total) were mainly enriched in
DNA replication, DNA repair, the cell cycle, cell division and expression regulation. These genes were also analyzed by the DAVID database, and the Gene Ontology (GO) and Kyoto Encyclopedia of Genes and Genomes (KEGG) enrichment results ( $p$-value $<0.05$, false discovery rate $<0.05)$ are shown in Table 4 , Table 5, Table 6 and Table 7. The MCM-related genes were significantly enriched in 21 biological processes, 5 cellular components, 14 molecular functions and 5 important KEGG pathways.

\section{PPI network construction and screening of hub genes}

As shown in Fig. 12, the PPI network was successfully constructed. There were 4 Molecular Complex 


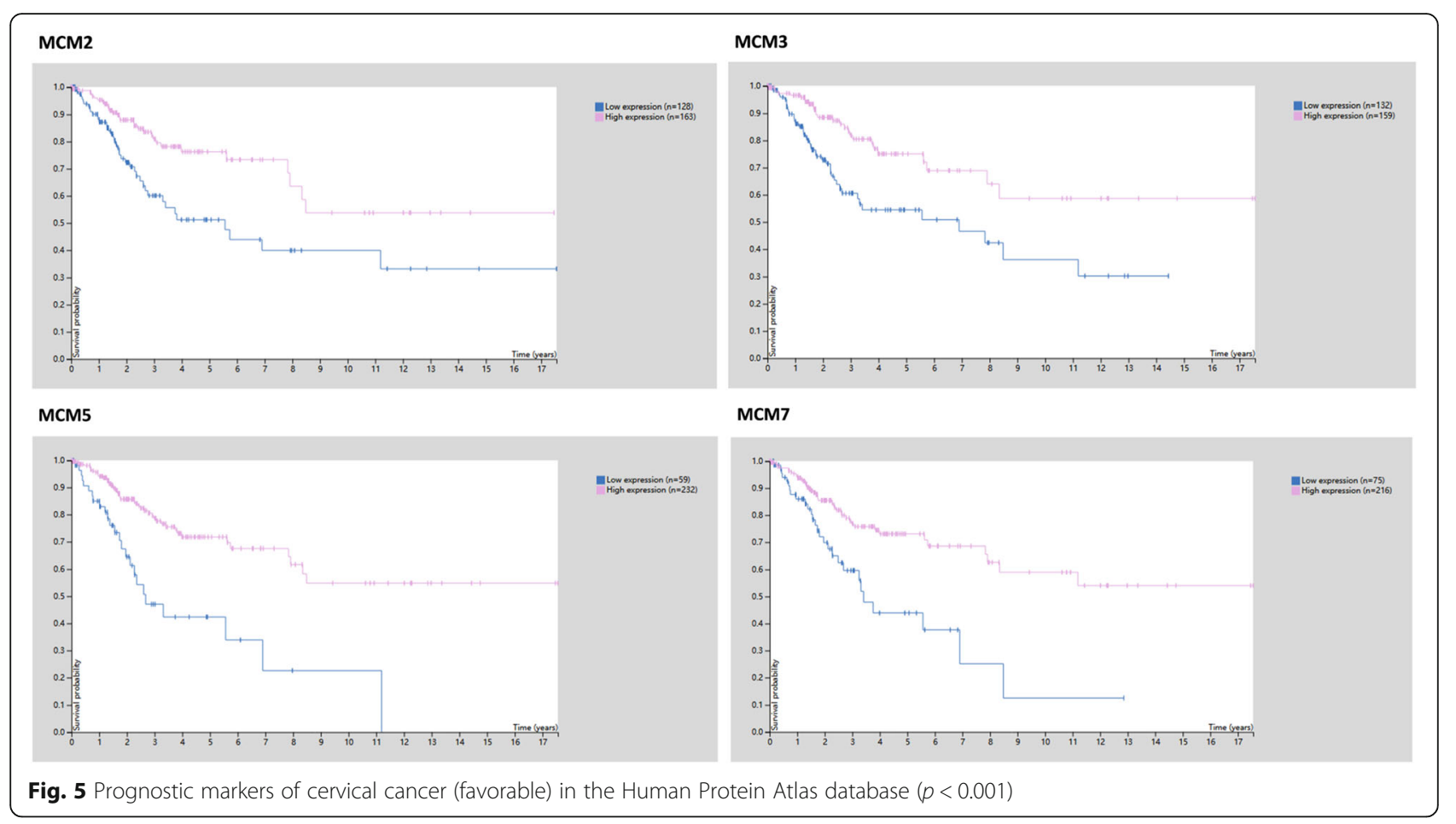

Detection (MCODE) components identified from the PPI network. MCODE 1 (MCM2/3/4/5/6/7/8, CLSPN, $C D C 45$, ORC1, RPA1, and CDT1) played an important role in the activation of the prereplicative complex (R-HSA-68962), the activation of ATR in response to replication stress (R-HSA-176187) and DNA replication preinitiation (R-HSA-69002). MCODE 2 (TARDBP, RBMX, U2AF2, HNRNPM, SRSF3, and SRSF1) was important in the regulation of mRNA metabolic processes (GO:1903311) and spliceosomes (ko03040, hsa03040). MCODE 3 (USP1, $R F C 5$, and $R F C 2$ ) was important in the recognition of DNA damage by the PCNA-containing replication complex (R-HSA-110314), DNA damage response (GO:0042769) and PID Fanconi pathway (M1). MCODE 4 (MSH6, DTL, and MSH2) was important in the response to UV (GO:0009411), the response to light stimulus (GO:0009416) and DNA repair (RHSA-73894). The survival analysis results of the hub genes from the $4 \mathrm{MCODE}$ components are shown in Fig. 13 (the prognostic value of MCMs is shown in Fig. 8 and Fig. 9). The expression of HNRNPM, $U 2 A F 2$, USP1 and CLSPN showed no correlation with the prognosis of CESC patients, while the high expression of the other 13 genes was significantly related to a better prognosis. Moreover, higher mRNA expression of RFC5, RFC2, DTL, RBMX, ORC1 and $M S H 2$ was significantly associated with longer OS in CESC patients. These results indicated that the hub genes might play an important role in cervical cancer and provide potential molecular targets. In addition, GEPIA2 was used to generate an interactive heat map of the expression of MCMs and related genes in different cancer types (Fig. 14). The hub genes and MCM2/3/4/5/6/7/8 might have potential clinical value for the survival and prognosis of cervical cancer patients.

\section{Discussion}

Cervical cancer is the most common cancer among women worldwide. High-risk human papillomavirus (HPV) infection causes high morbidity and mortality. Therefore, the development of cervical cancer vaccines and screening technology and the exploration of clinical targets with good application prospects are still important. MCMs are implicated in the development of multiple cancers, including cervical cancer. Thus, MCM proteins have emerged as exceptionally promising markers for cervical cancer screening and early diagnosis [34]. Mitali Das et al. [35] explored the role of MCM4/5/6/10 in cervical cancer and their correlation with the clinical parameters of cervical cancer, and further study indicated that cervical cancer cells may use excess MCMs as a backup for replicative stress [36]. V N Saritha et al. [37] showed that $\mathrm{MCM} 2 / 5$ expression was upregulated in low-grade lesions, high-grade lesions and malignancies to a greater extent than p16 and p63. Gurjeet Kaur et al. 

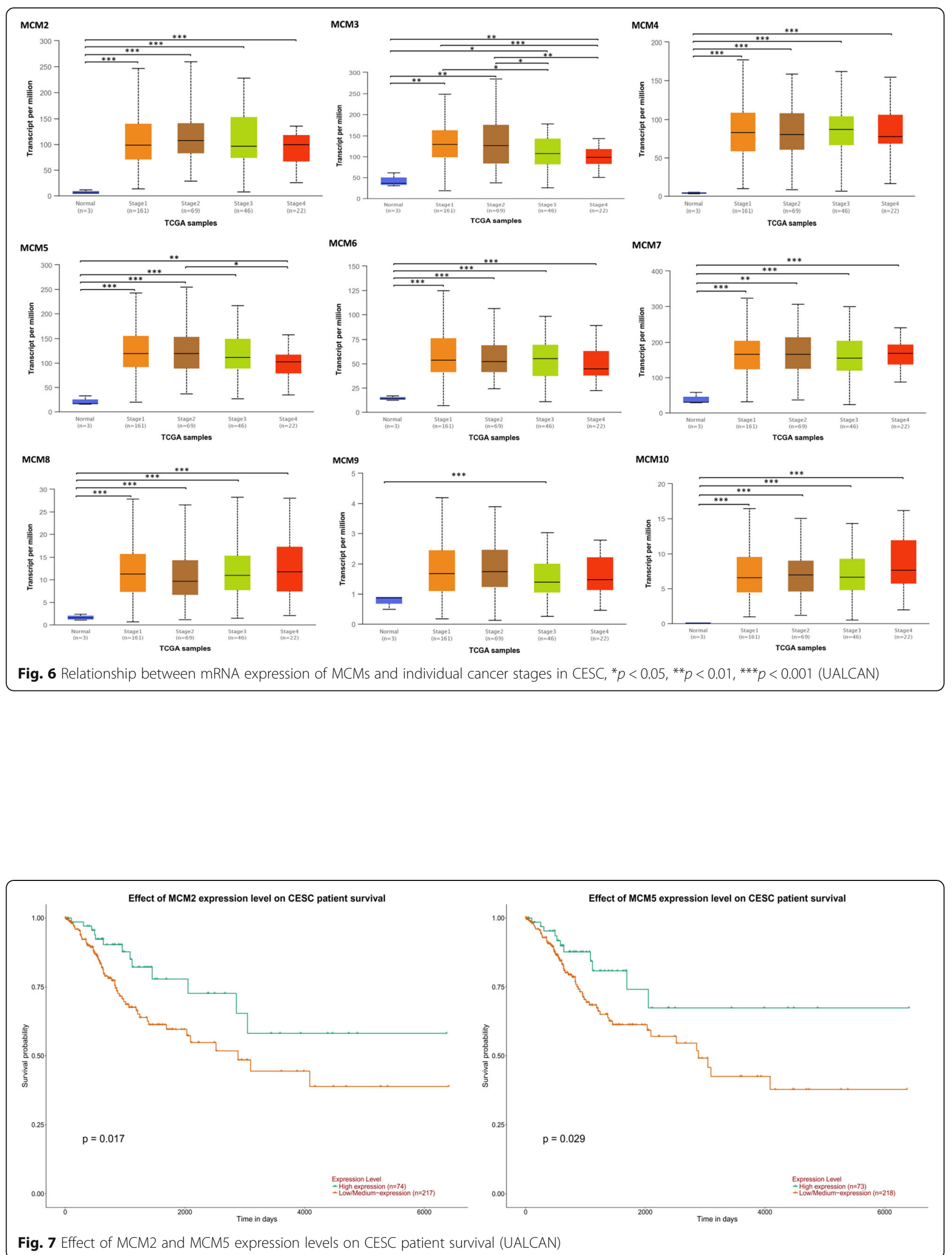

Fig. 7 Effect of MCM2 and MCM5 expression levels on CESC patient survival (UALCAN) 


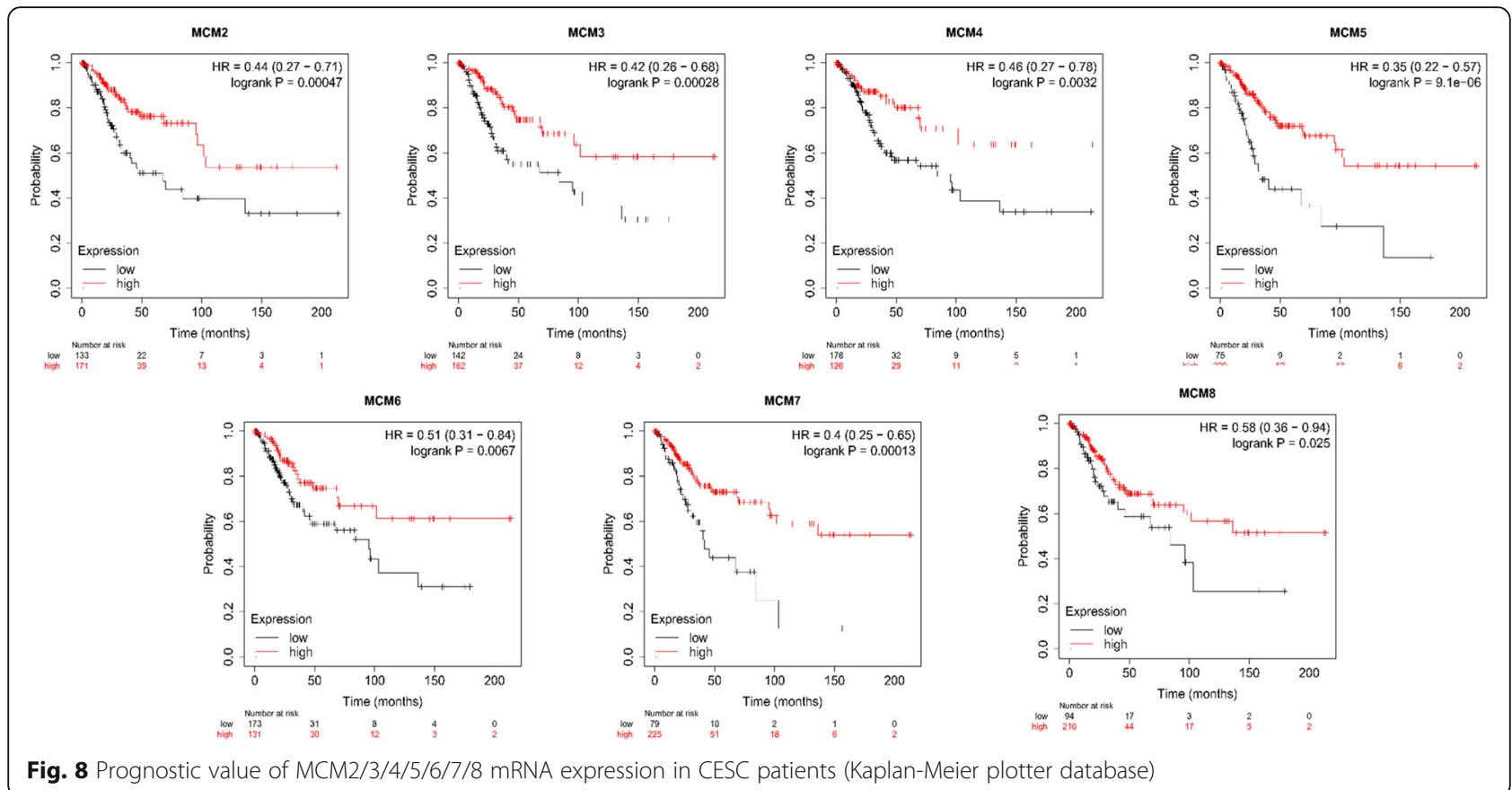

[38] evaluated MCM gene expression profiles and MCM2 protein in HPV-associated cervical carcinogenesis. There is growing evidence that MCMs may be used as biomarkers to predict the malignant potential of cervical lesions. However, as cervical cancer is a complex disease involving many molecular interactions and complex signaling pathways, reports of MCMs and their related genes in cervical cancer are few and insufficient, and more research is still needed for the prevention and treatment of cervical cancer. In this study, bioinformatics was used to mine expression data and perform subsequent comprehensive analyses, which were based on a large amount of public data of patients with cervical cancer, for the in-depth study of the related molecular mechanisms of MCMs and protein molecular interactions, the prediction of related biomarkers, and the exploration of factors related to the good survival and prognosis of patients.

The expression of different MCMs in cervical cancer patients obtained from professional databases (ONCOMINE, UALCAN and HPA) showed that the

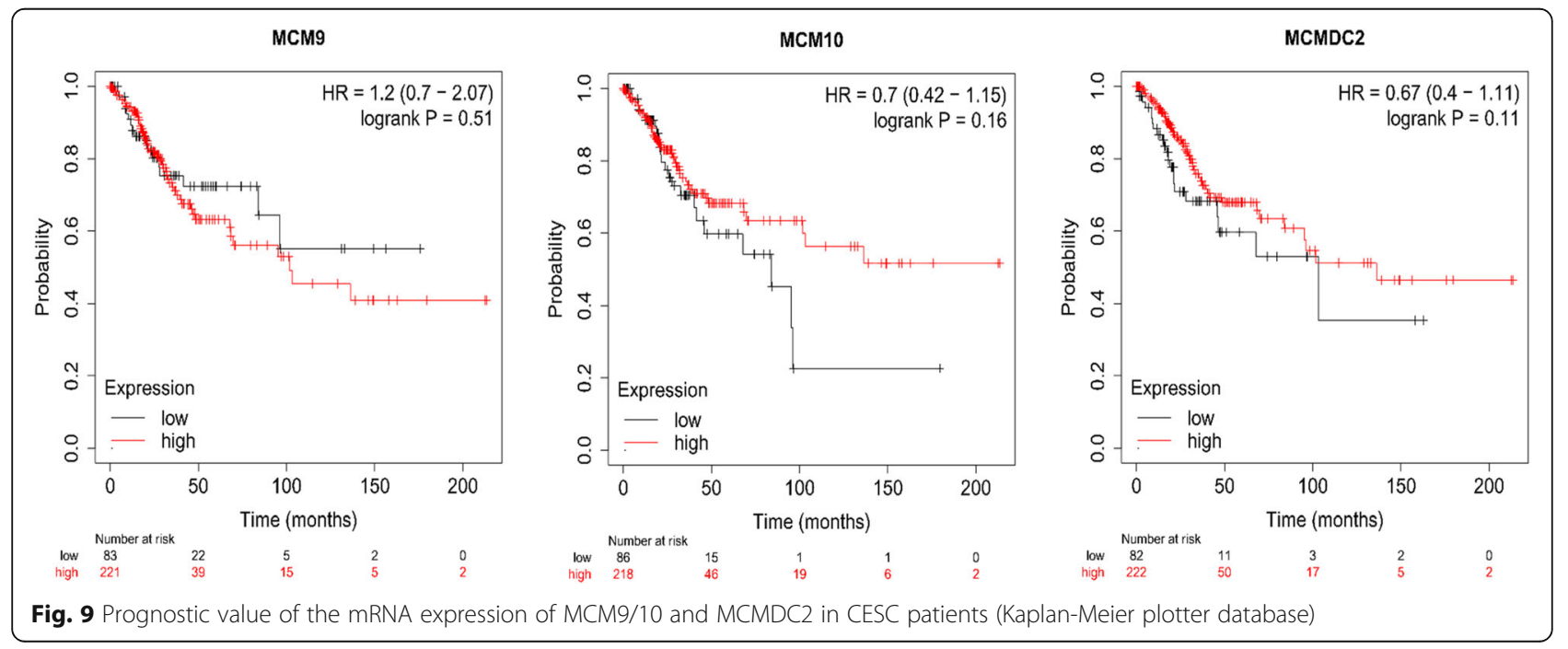




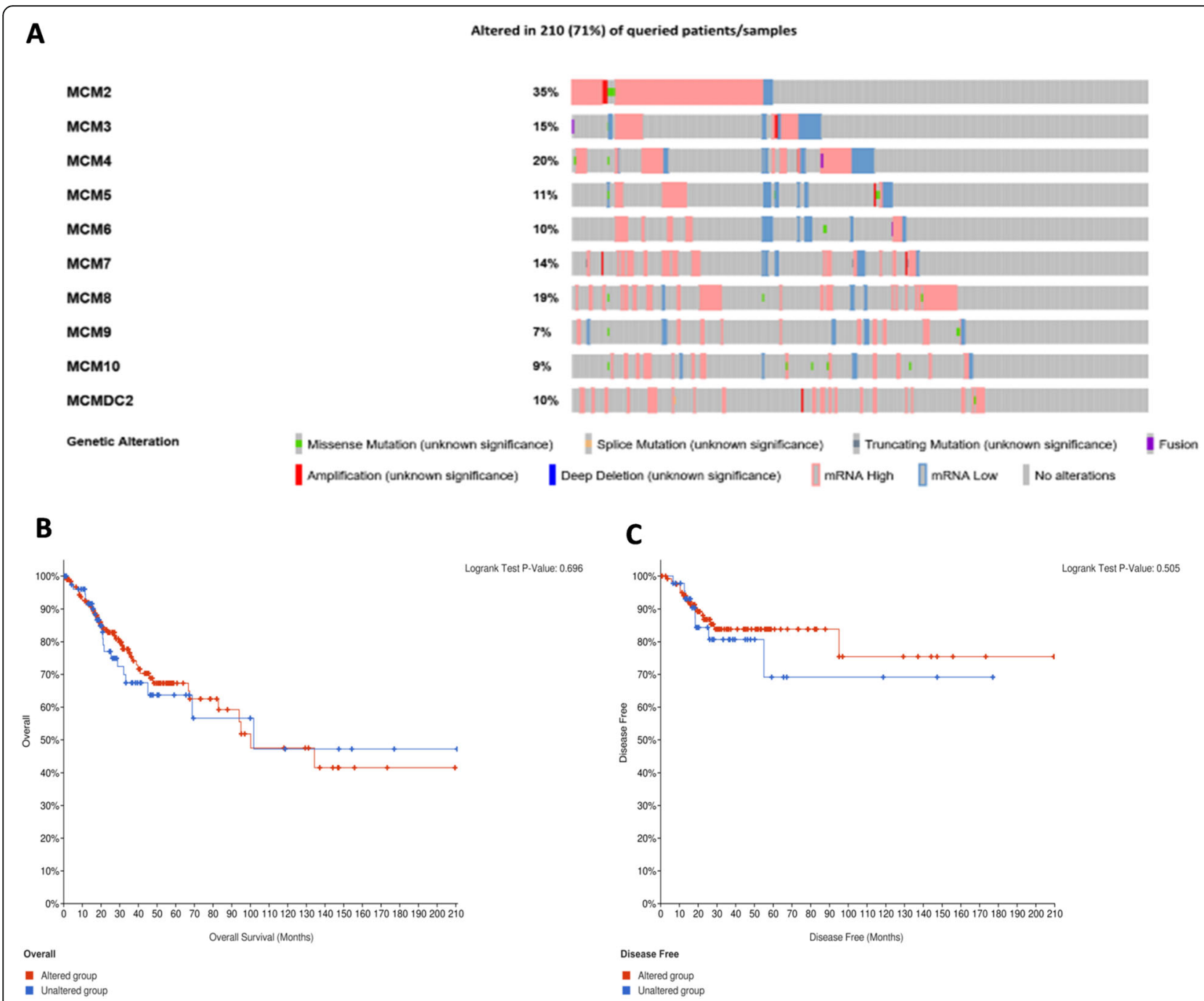

Fig. 10 Analysis of MCMs in CESC patients (cBioPortal). A. Genetic mutations; B. Relationships between MCM gene mutations and OS and DFS in CESC patients (cBioPortal)

mRNA and protein expression of MCMs increased in tumor tissue. These findings promoted our understanding of the expression of different MCMs in cancer patients. In particular, to evaluate and predict the potential clinical value of MCMs, analyses of individual cancer stages, the survival of cancer patients and the genetic alterations of different MCMs were performed using the UALCAN, Kaplan-Meier plotter and cBioPortal databases. The multidatabase analysis revealed that MCMs had great potential clinical significance. MCM2/3/4/5/6/7/8 might be used as potential indicators for survival in patients with cervical cancer, which needs more research and verification. Moreover, a high mutation rate $(71 \%)$ of MCMs was observed in cervical cancer patients. MCM2, MCM4, MCM8, MCM3 and MCM7 ranked as the top five genes with the highest number of genetic alterations, but genetic alterations in MCMs were not significantly associated with longer OS or DFS in CESC patients. According to these results, the intervention strategy of mutating MCM genes to achieve longer survival times in patients might not be effective. However, controlling the gene transcription and protein expression of MCMs might be an effective intervention method for CESC patients.

After the expression analysis and clinical value evaluation of MCMs, the coexpressed genes and related genes of MCMs were screened by cBioPortal and GEPIA2 analysis, and then the systematic enrichment analysis of related genes was performed by Metascape and the DAVID database to deepen the understanding of the role of MCMs and related genes 
Table 2 Intersection analysis of the coexpressed genes of MCMs in CESC (CBioPortal)

\begin{tabular}{|c|c|c|}
\hline Groups & Total & Intersection elements \\
\hline $\begin{array}{l}\mathrm{MCM} 2 / \\
6 / 7\end{array}$ & 1 & MCM5 \\
\hline $\begin{array}{l}\mathrm{MCM} 3 / \\
5 / 6\end{array}$ & 1 & CHAFIB \\
\hline $\begin{array}{l}\text { MCM5/ } \\
6 / 7\end{array}$ & 2 & MCM2, GINS2 \\
\hline $\mathrm{MCM} 3 / 5$ & 1 & MCM6 \\
\hline MCM3/6 & 3 & RFC5, FANCC, TIMELESS \\
\hline MCM4/8 & 3 & CLSPN, BRIP1, RBLI \\
\hline MCM5/7 & 3 & $C D T 1, R F C 2, C D C 45$ \\
\hline MCM6/7 & 1 & ORC1 \\
\hline MCM6/8 & 1 & TOP2A \\
\hline MCM2 & 24 & $\begin{array}{l}\text { HMCES, COMMD2, GMPS, RYK, PIK3R4, MSL2, UMPS, DBR1, TBCCD1, HLTF, ZXDC, TOPBP1, TFDP2, RFC4, NAA50, EEFSEC, ACAD9, ARMC8, } \\
\text { MBD4, RUVBL1, H1FX, SEC22A, ISY1, ASTE1 }\end{array}$ \\
\hline MCM3 & 20 & $\begin{array}{l}\text { PRSS16, DEK, ORC3, PPP2R5D, CHAF1A, CDC5L, TJAP1, CENPQ, CCHCR1, MAD2L1BP, MMUT, NUP85, NASP, CDKAL1, KIFC1, OARD1, GMNN, } \\
\text { LOC730101, KLHDC3, PRIM2 }\end{array}$ \\
\hline MCM4 & 22 & $\begin{array}{l}\text { UBR5, CKAP2L, CCDC107, GTF2A1, MTBP, TAF2, RIF1, CCNE2, NCOA2, WDHD1, ATAD2, KNL1, PRR11, TGS1, SMC3, FKBP2, WASHC5, RAD21, } \\
\text { VPS13B, PRKDC, DHX9, ARMC1 }\end{array}$ \\
\hline MCM5 & 18 & $\begin{array}{l}\text { TFIP11, FANCE, EWSR1, XRCC6, ESS2, EIF3D, NCAPH2, PICK1, SLC3OA1, L3MBTL2, DMC1, POLA2, NOL12, CENPM, POLD1, RBX1, MCM7, } \\
\text { TBC1D22A }\end{array}$ \\
\hline MCM6 & 16 & TYMS, CDCA7, MCM3, RIBC2, MTHFD1, DTL, UHRF1, PRIM1, PCNA, SMPD4, DNMT1, UNG, USP1, WDR76, MSH6, HAT1 \\
\hline MCM7 & 18 & TRIP6, PIN1, KIF22, SRRT, LAMTOR4, DCTPP1, PDAP1, MDH2, NSUN5, ORC5, GNB2, RAD54L, MEPCE, MYBL2, CDCA5, CPSF4, BUD31, POP7 \\
\hline MCM8 & 21 & $\begin{array}{l}\text { ALMS1, CYB5RL, CSNK2A3, ESF1, XRN2, DHX35, ATAD5, RALGAPB, ANKEF1, NANP, GINS1, FAM217B, BARD1, SLX4IP, RPRD1B, PTPRA, RBBP9, } \\
\text { TAF1, STK35, ATRN, ADNP }\end{array}$ \\
\hline
\end{tabular}

in cervical cancer. A total of 59 genes were involved in the enrichment analysis. The enrichment results revealed that these genes played an important role in DNA replication, the cell cycle, DNA repair, the DNA damage response, the regulation of signal transduction by $\mathrm{p} 53$ class mediators and other important biological processes. Moreover, these genes were significantly enriched in some important cellular components, such as the nucleoplasm, nucleus, MCM complex, nuclear chromosome, telomeric region and nuclear speck, which were also involved in DNA binding, DNA helicase activity, protein binding, ATP binding, nucleoside binding, DNA replication origin binding and RNA binding. We found that MCMs and their related genes were significantly enriched in some important pathways, such as the DNA replication (RFC5, MCM7, RFC2, PRIM1, RPA1, MCM3, MCM4, MCM5, $M C M 6$, and $M C M 2)$, cell cycle (RBL1, CDC45, MCM7, ORC1, MCM3, MCM4, MCM5, MCM6, and MCM2), mismatch repair (RFC5, MSH6, MSH2, RFC2, and RPA1), spliceosome (HNRNPM, U2AF2, SRSF1, HNRNPU, SRSF3, and RBMX) and Fanconi anemia (BRIP1, RPA1, USP1, and FANCC) pathways. Further study of these pathways can deepen the understanding of the molecular mechanisms related to the occurrence and development of cervical cancer.

In the current study, genes coexpressed with MCMs and their related genes were successfully screened for

Table 3 Intersection analysis of the related genes and key coexpressed genes of MCMs in CESC

\begin{tabular}{|c|c|c|}
\hline Groups & Total & Intersection elements \\
\hline Common genes & 9 & RFC5, MCM5, MCM6, TIMELESS, FANCC, MCM2, ORC1, CLSPN, BRIP1 \\
\hline $\begin{array}{l}\text { Key coexpressed } \\
\text { genes }\end{array}$ & 7 & CHAF1B, RBL1, GINS2, TOP2A, CDT1, RFC2, CDC45 \\
\hline Related genes & 41 & $\begin{array}{l}\text { PPM1D, RBBP4, ZWINT, TMPO, TOPBP1, U2AF2, DEK, SRSF3, MCM3, HCFC1, MSH2, TUBA1B, DCAF11, THRAP3, SART3, CPSF6, } \\
\text { MIS18BP1, CTCF, SAP130, LMNB1, ATAD55, DCLRE1B, ADNP, MCM4, DTL, MSH6, NRF1, HMGXB4, ZNF367, UNG, HNRNPM, SRSF1, } \\
\text { TARDBP, RPA1, SENP1, USP1, RFWD3, RBMX, HNRNPU, PRIM1, UHRF1 }\end{array}$ \\
\hline
\end{tabular}




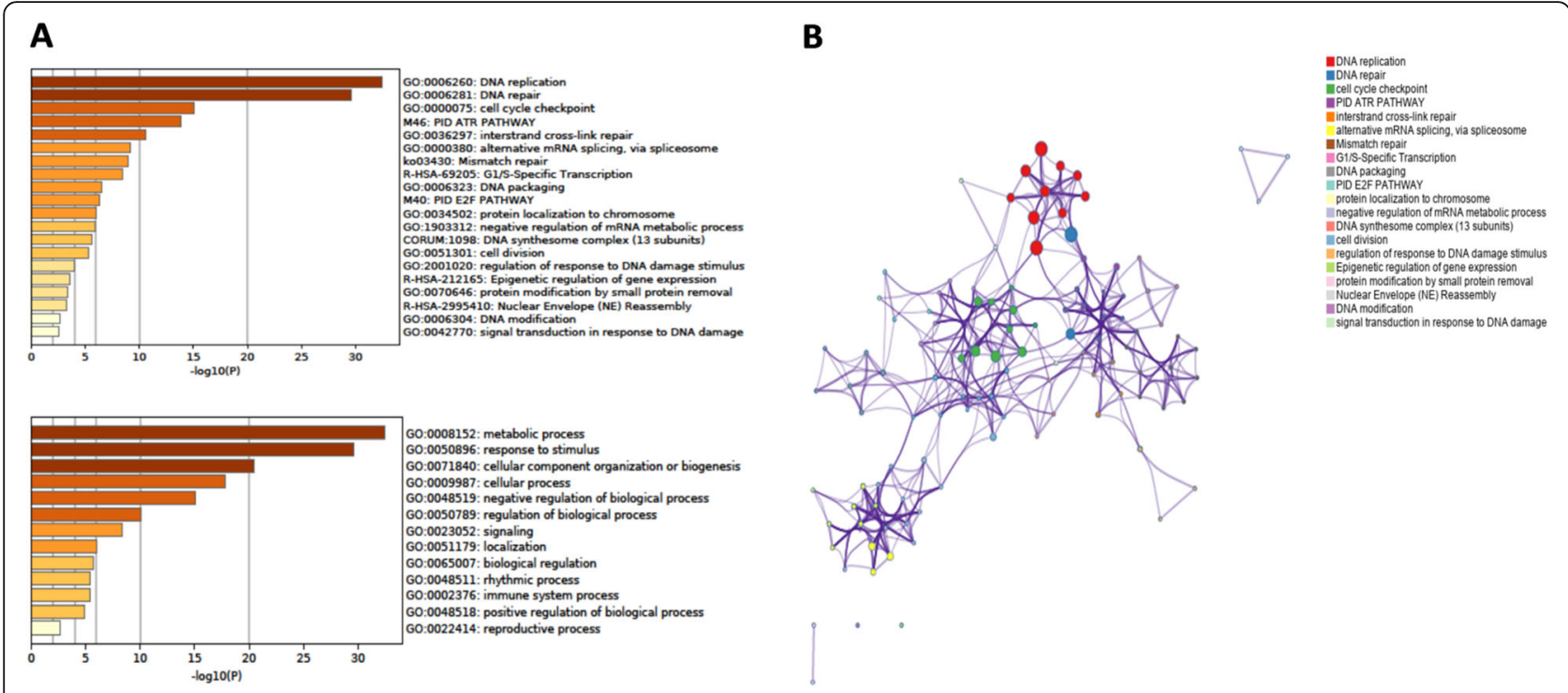

Fig. 11 Enrichment results of the hub genes. A. Bar graph of the enriched terms (the top 20 clusters) and the top-ranked Gene Ontology biological processes; B. Network of the enriched terms colored by cluster ID. Nodes that share the same cluster ID are typically close to each other (Metascape)

Table 4 GO enrichment analysis and the significant terms (biological processes)

\begin{tabular}{|c|c|c|}
\hline Term & Count & $P$-value \\
\hline GO:0006260 DNA replication & 21 & $5.08 \mathrm{E}-27$ \\
\hline GO:0006270 DNA replication initiation & 10 & $8.09 \mathrm{E}-16$ \\
\hline GO:0000082 G1/S transition of mitotic cell cycle & 12 & $3.50 \mathrm{E}-14$ \\
\hline GO:0006281 DNA repair & 11 & $5.78 \mathrm{E}-09$ \\
\hline GO:0006268 DNA unwinding involved in DNA replication & 5 & 2.47E-08 \\
\hline GO:0042769 DNA damage response, detection of DNA damage & 5 & $6.48 \mathrm{E}-06$ \\
\hline GO:0032508 DNA duplex unwinding & 5 & $1.46 \mathrm{E}-05$ \\
\hline GO:0016447 somatic recombination of immunoglobulin gene segments & 3 & 3.39E-05 \\
\hline GO:1901796 regulation of signal transduction by p53 class mediator & 6 & $6.24 \mathrm{E}-05$ \\
\hline GO:0006974 cellular response to DNA damage stimulus & 7 & $7.21 \mathrm{E}-05$ \\
\hline GO:0000398 mRNA splicing, via spliceosome & 7 & 1.03E-04 \\
\hline GO:0000722 telomere maintenance via recombination & 4 & $1.72 \mathrm{E}-04$ \\
\hline GO:0019985 translesion synthesis & 4 & 2.45E-04 \\
\hline GO:0036297 interstrand cross-link repair & 4 & $6.12 \mathrm{E}-04$ \\
\hline GO:0007049 cell cycle & 6 & 8.35E-04 \\
\hline GO:0016446 somatic hypermutation of immunoglobulin genes & 3 & 0.001318 \\
\hline GO:0070987 error-free translesion synthesis & 3 & 0.001865 \\
\hline GO:0042276 error-prone translesion synthesis & 3 & 0.001865 \\
\hline GO:0000083 regulation of transcription involved in G1/S transition of mitotic cell cycle & 3 & 0.002736 \\
\hline GO:0006297 nucleotide-excision repair, DNA gap filling & 3 & 0.002978 \\
\hline GO:0006397 mRNA processing & 5 & 0.003176 \\
\hline
\end{tabular}


Table 5 GO enrichment analysis and the significant terms (cellular components)

\begin{tabular}{lll}
\hline Term & Count & $P$-value \\
\hline GO:0005654 nucleoplasm & 50 & $1.78 \mathrm{E}-31$ \\
GO:0005634 nucleus & 44 & $3.49 \mathrm{E}-12$ \\
GO:0042555 MCM complex & 6 & $3.42 \mathrm{E}-11$ \\
GO:0000784 nuclear chromosome, telomeric region & 10 & $2.87 \mathrm{E}-10$ \\
GO:0016607 $\sim$ nuclear speck & 6 & $4.43 \mathrm{E}-04$ \\
\hline
\end{tabular}

Table 6 GO enrichment analysis and the significant terms (molecular functions)

\begin{tabular}{lll}
\hline Term & Count & $P$-value \\
\hline GO:0003677 DNA binding & 23 & $1.21 \mathrm{E}-08$ \\
GO:0003678 DNA helicase activity & 6 & $1.62 \mathrm{E}-08$ \\
GO:0005515 protein binding & 51 & $4.03 \mathrm{E}-08$ \\
GO:0003697 single-stranded DNA binding & 7 & $7.63 \mathrm{E}-07$ \\
GO:0003682 chromatin binding & 10 & $6.83 \mathrm{E}-06$ \\
GO:0005524 ATP binding & 17 & $2.92 \mathrm{E}-05$ \\
GO:0042393 histone binding & 6 & $6.13 \mathrm{E}-05$ \\
GO:0003684 damaged DNA binding & 5 & $6.42 \mathrm{E}-05$ \\
GO:0004003 ATP-dependent DNA helicase activity & 4 & $1.78 \mathrm{E}-04$ \\
GO:0000166 nucleotide binding & 8 & $1.81 \mathrm{E}-04$ \\
GO:0003688 DNA replication origin binding & 3 & $6.26 \mathrm{E}-04$ \\
GO:0019899 enzyme binding & 7 & $9.62 \mathrm{E}-04$ \\
GO:0044822 poly(A) RNA binding & 12 & 0.001415 \\
GO:0003723 $~$ RNA binding & 8 & 0.002595 \\
\hline
\end{tabular}

Table 7 Significant KEGG signaling pathways

\begin{tabular}{lll}
\hline Term & Count & P-value \\
\hline hsa03030: DNA replication & 10 & $9.33 \mathrm{E}-15$ \\
hsa04110: Cell cycle & 9 & $2.78 \mathrm{E}-08$ \\
hsa03430: Mismatch repair & 5 & $2.13 \mathrm{E}-06$ \\
hsa03040: Spliceosome & 6 & $2.05 \mathrm{E}-04$ \\
hsa03460: Fanconi anemia pathway & 4 & 0.001369866 \\
\hline
\end{tabular}

PPI network construction. A total of 4 key subnetworks were screened. Survival analysis showed that 13 hub genes (CDC45, ORC1, RPA1, CDT1, TARDBP, RBMX, SRSF3, SRSF1, RFC5, RFC2, MSH6, DTL, and MSH2) from the key subnetworks might have potential clinical value. These genes and MCM2/3/4/5/6/7/8 were significantly related to the survival and prognosis of cervical cancer patients. Thus, our results might provide bioinformatics support for MCMs and their related genes in the prevention and clinical treatment of cervical cancer.

However, this study had three limitations. First, the data analyzed in this study were from public databases, and the analysis results might be affected by the quantity and quality of the data. Second, we did not evaluate the potential therapeutic or diagnostic effects of MCMs in detail. Finally, we did not explore the potential mechanisms of MCMs and hub genes in cervical cancer in detail, and the effect on prognosis requires follow-up data. Therefore, further research is needed to verify our findings and to explore the clinical application of MCMs and their related genes for the treatment of cervical cancer.

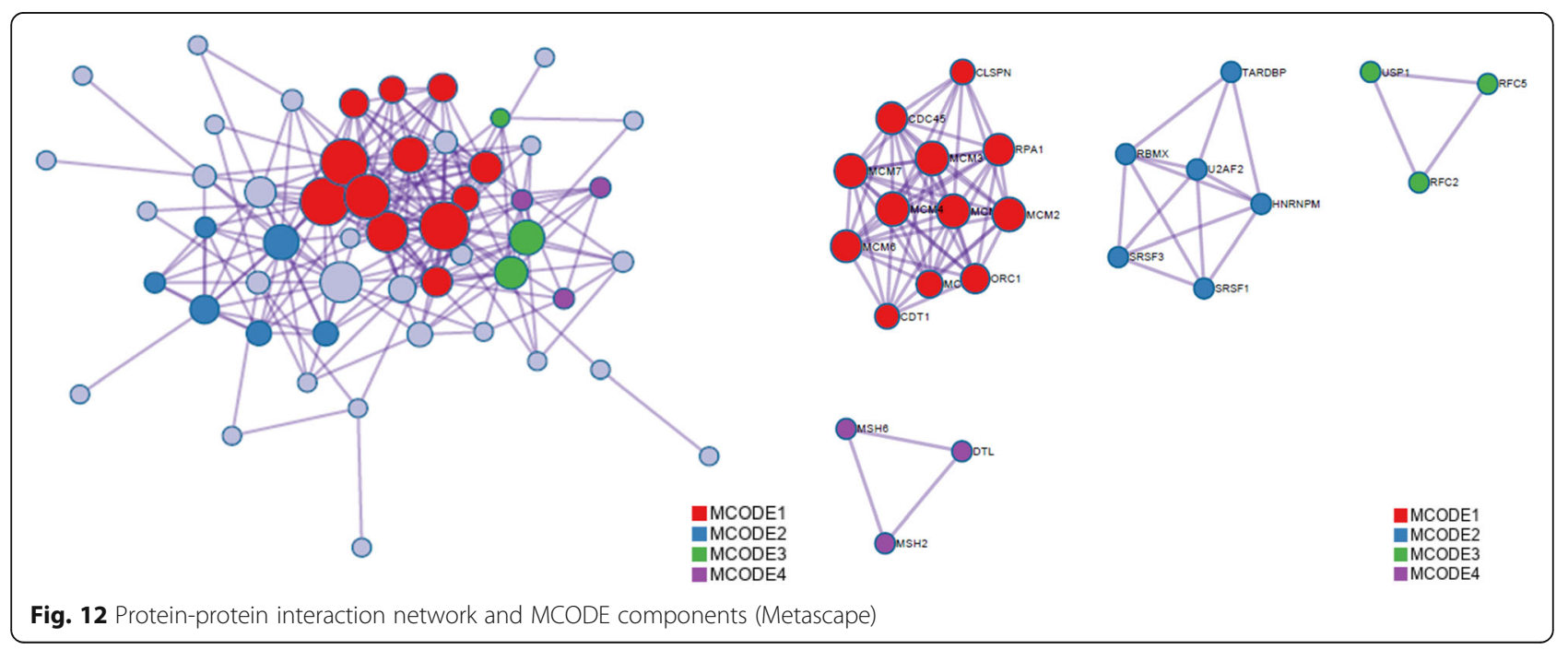




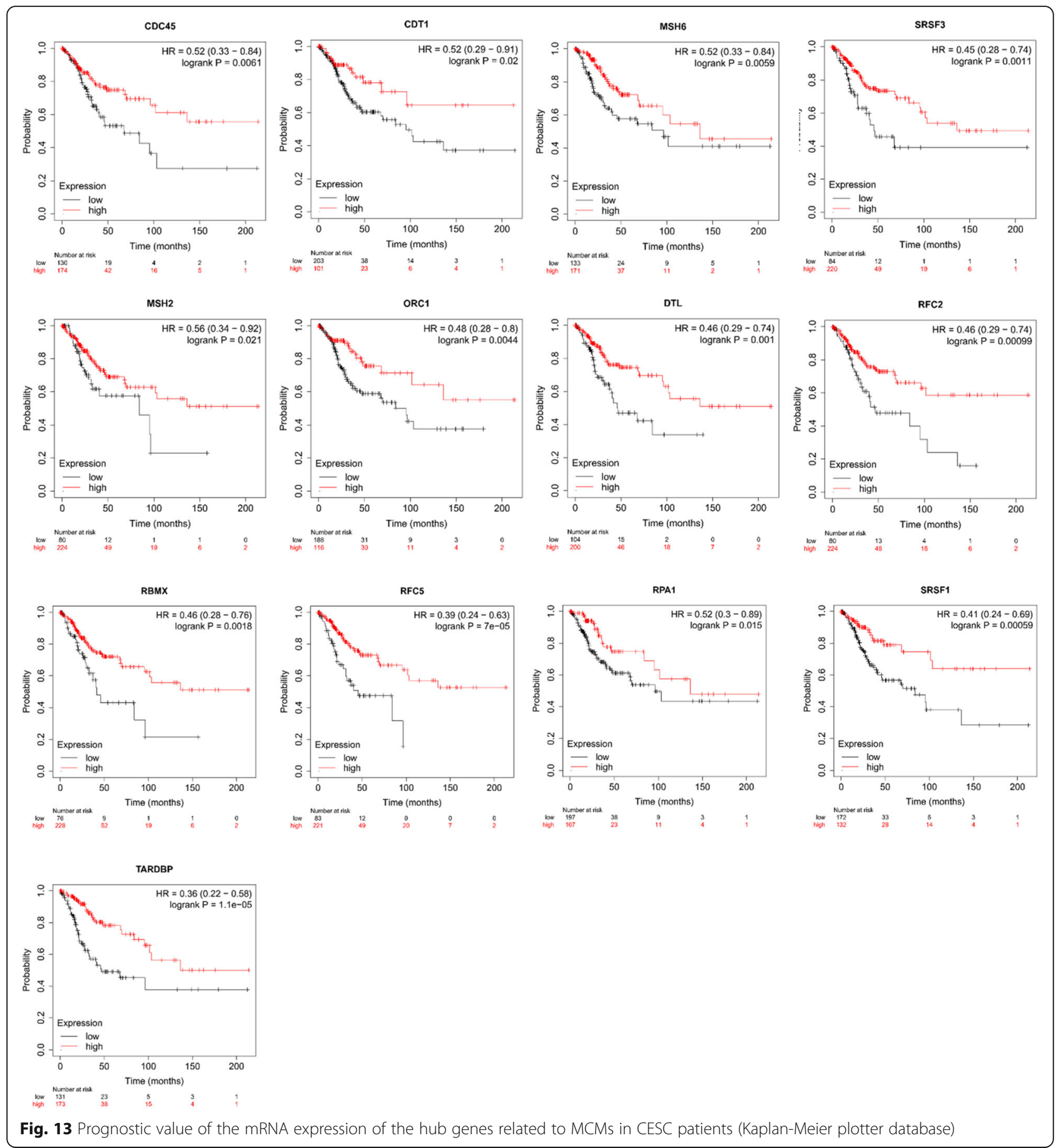

\section{Conclusion}

In conclusion, this study used a variety of bioinformatics methods to explore the transcriptional expression of MCMs as potential indicators of survival in patients with cervical cancer, obtained target genes with potential application value, and deepened the understanding of the influence of MCMs and their related genes in cervical cancer. These genes can be used to diagnose the progression of the disease before it leads to cancer. Moreover, our findings promoted the understanding of the MCM protein family and clinically related molecular targets for cervical epithelial neoplasia and cervical cancer, which provided new insight into the biological functions of MCMs in cervical cancer. 


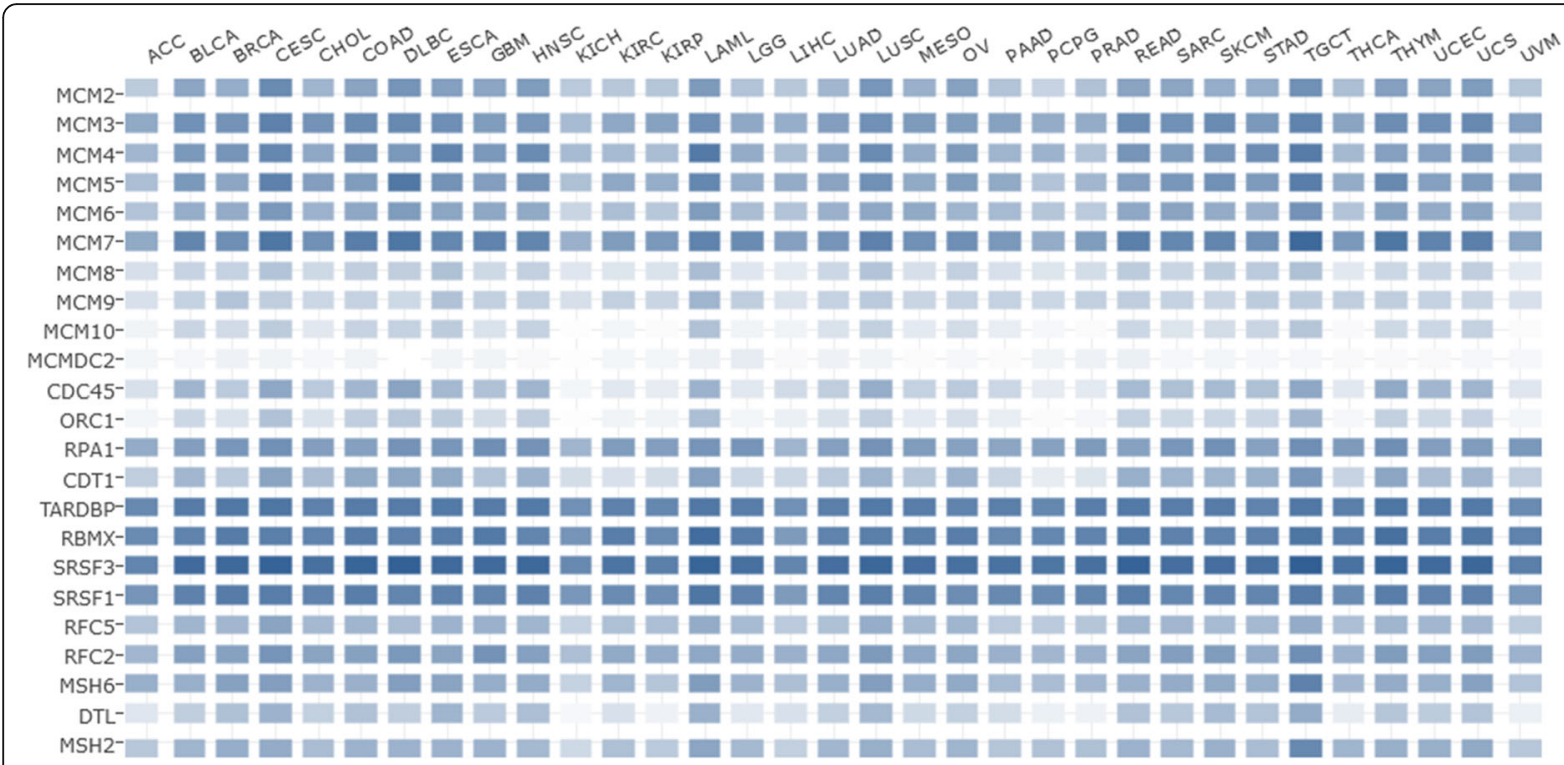

Fig. 14 Interactive heat map analysis of tissue-wise expression in different cancer types (GEPIA2)

\section{Abbreviations}

MCM: minichromosome maintenance; MCMDC2: MCM domain-containing 2; GO: Gene Ontology; KEGG: Kyoto Encyclopedia of Genes and Genomes; PPI: protein-protein interaction; CESC: cervical squamous cell carcinoma; HPA: Human Protein Atlas; DAVID: Database for Annotation, Visualization and Integrated Discovery; TCGA: The Cancer Genome Atlas; OS: overall survival; DFS: disease-free survival; MCODE: Molecular Complex Detection; HPV: Human papillomavirus; CESCE: cervical squamous cell carcinoma epithelia; HG-CIN: high-grade cervical squamous intraepithelial neoplasia epithelia

\section{Acknowledgments}

We thank the company leaders for their support and the editors and reviewers for their time spent handling and reviewing this manuscript. We also acknowledge the ONCOMINE database, UALCAN database, Human Protein Atlas database, Kaplan-Meier plotter database, cBioPortal databases, DAVID database, KEGG database and GEPIA2 database for providing public data and Metascape and the Venn diagram tool for providing analytical tools.

\section{Authors' contributions}

Conceived and designed the study: BW and SX. Analyzed the data: BW. Interpreted/analyzed the data and results: BW. Wrote the paper: BW. All authors reviewed and approved the final manuscript.

\section{Authors' information}

Corresponding author and first author: Baojie Wu (June 1987), male, senior engineer of the Pilot Department, Master's degree in biochemistry and molecular biology, mainly engaged in optimization of the purification process, amplification of the purification process, and bioinformatics data mining. Email:w3522021987@163.com, zrwbj@walvax.com. Second author: Shuyi Xi (February 1978), male, department head, mainly engaged in management of the Pilot Department. Email: xishuyi@walvax.com. The authors are committed to the study of HPV vaccines.

\section{Funding}

Not applicable. The funding source played no role in the design of the study, the collection, analysis, and interpretation of the data, or the writing of the manuscript.

\section{Availability of data and materials}

The data used for analysis were all from online public databases and could be retrieved. Based on these data, we conducted further analysis and research. The datasets generated and analyzed during the current study are available in the ONCOMINE database, UALCAN database, Human Protein Atlas database, Kaplan-Meier plotter database, and GEPIA2 database repository. Preliminary enrichment analysis, molecular interaction network construction and hub gene screening were performed via the Metascape website, and the DAVID database was used for further verification. The websites of the databases are as follows: [https://www.oncmine.org], [http://ualcan.path. uab.edu/], [https://www.proteinatlas.org/], [http://kmplot.com/analysis], [https://metascape.org/gp/index.html], [https://david.ncifcrf.gov/], and [http:// gepia2.cancer-pku.cn].

\section{Declaration}

Ethics approval and consent to participate Not applicable.

\section{Consent for publication}

Not applicable.

\section{Competing interests}

The authors declare that there are no competing interests.

Received: 29 January 2021 Accepted: 10 August 2021 Published online: 18 August 2021

\section{References}

1. Forsburg SL. Eukaryotic MCM proteins: beyond replication initiation. Microbiol Mol Biol Rev. 2004;68(1):109-31. https://doi.org/10.1128/MMBR. 68.1.109-131.2004.

2. Miller JM, Arachea BT, Epling LB, Enemark EJ. Analysis of the crystal structure of an active MCM hexamer. Elife. 2014;3:e03433. https://doi.org/10.7554/ elife.03433.

3. Bell SD, Botchan MR. The minichromosome maintenance replicative helicase. Cold Spring Harb Perspect Biol. 2013;5(11):a012807. https://doi. org/10.1101/cshperspect.a012807.

4. Griffin WC, Trakselis MA. The MCM8/9 complex: a recent recruit to the roster of helicases involved in genome maintenance. DNA Repair (Amst). 2019;76: 1-10. https://doi.org/10.1016/j.dnarep.2019.02.003.

5. Finsterbusch F, Ravindranathan R, Dereli I, Stanzione M, Tränkner D, Tóth A. Alignment of homologous chromosomes and effective repair of programmed DNA double-Strand breaks during mouse meiosis require the Minichromosome maintenance domain containing 2 (MCMDC2) protein. 
PLoS Genet. 2016;12(10):e1006393. https://doi.org/10.1371/journal.pgen.1 006393.

6. Baxley RM, Bielinsky AK: Mcm10: A Dynamic Scaffold at Eukaryotic Replication Forks. Genes (Basel). 2017:8(2):73.

7. Malinowski DP. Molecular diagnostic assays for cervical neoplasia: emerging markers for the detection of high-grade cervical disease. Biotechniques. 2005;Suppl:17-23.

8. Zheng J. Diagnostic value of MCM2 immunocytochemical staining in cervical lesions and its relationship with HPV infection. Int J Clin Exp Pathol. 2015;8(1):875-80

9. Wang $\mathrm{D}, \mathrm{Li} \mathrm{Q}, \mathrm{Li} Y$, Wang $\mathrm{H}$. The role of MCM5 expression in cervical cancer: correlation with progression and prognosis. Biomed Pharmacother. 2018;98: 165-72. https://doi.org/10.1016/j.biopha.2017.12.006.

10. Rhodes DR, Yu J, Shanker K, Deshpande N, Varambally R, Ghosh D, et al. ONCOMINE: a cancer microarray database and integrated data-mining platform. Neoplasia. 2004;6(1):1-6. https://doi.org/10.1016/S1476-5586(04 )80047-2.

11. Chandrashekar DS, Bashel B, Balasubramanya SAH, Creighton CJ, PonceRodriguez I, Chakravarthi B, et al. UALCAN: a portal for facilitating tumor subgroup gene expression and survival analyses. Neoplasia. 2017;19(8):64958. https://doi.org/10.1016/.neo.2017.05.002

12. Uhlén M, Fagerberg L, Hallström BM, Lindskog C, Oksvold P, Mardinoglu A, et al. Proteomics. Tissue-based map of the human proteome. Science. 2015; 347(6220):1260419.

13. Thul PJ, Åkesson L, Wiking M, Mahdessian D, Geladaki A, Ait Blal H, Alm T, Asplund A, Björk L, Breckels LM, et al. A subcellular map of the human proteome. Science. 2017;356(6340):eaal3321.

14. Uhlen M, Zhang C, Lee S, Sjöstedt E, Fagerberg L, Bidkhori G, Benfeitas R, Arif M, Liu Z, Edfors F et, al. A pathology atlas of the human cancer transcriptome. Science. 2017;357(6352):eaan2507.

15. Nagy Á, Lánczky A, Menyhárt O, Győrffy B. Validation of miRNA prognostic power in hepatocellular carcinoma using expression data of independent datasets. Sci Rep. 2018;8(1):9227. https://doi.org/10.1038/s41598-018-27521-y.

16. Nagy Á, Munkácsy G, Györffy B. Pancancer survival analysis of cancer hallmark genes. Sci Rep. 2021;11(1):6047.

17. Cerami E, Gao J, Dogrusoz U, Gross BE, Sumer SO, Aksoy BA, et al. The cBio cancer genomics portal: an open platform for exploring multidimensional cancer genomics data. Cancer Discov. 2012;2(5):401-4. https://doi.org/10.11 58/2159-8290.CD-12-0095.

18. Gao J, Aksoy BA, Dogrusoz U, Dresdner G, Gross B, Sumer SO, et al. Integrative analysis of complex cancer genomics and clinical profiles using the cBioPortal. Sci Signal. 2013;6(269):pl1. https://doi.org/10.1126/scisignal.2004088.

19. Tang Z, Kang B, Li C, Chen T, Zhang Z. GEPIAZ: an enhanced web server for large-scale expression profiling and interactive analysis. Nucleic Acids Res. 2019:47(W1):W556-w560. https://doi.org/10.1093/nar/gkz430.

20. Zhou Y, Zhou B, Pache L, Chang M, Khodabakhshi AH, Tanaseichuk O, et al. Metascape provides a biologist-oriented resource for the analysis of systems-level datasets. Nat Commun. 2019;10(1):1523. https://doi.org/10.103 8/s41467-019-09234-6.

21. Hochberg Y, Benjamini Y. More powerful procedures for multiple significance testing. Stat Med. 1990;9(7):811-8. https://doi.org/10.1002/sim.4 780090710.

22. Dennis G Jr, Sherman BT, Hosack DA, Yang J, Gao W, Lane HC, et al. DAVID: database for annotation, visualization, and integrated discovery. Genome Biol. 2003;4(5):P3. https://doi.org/10.1186/gb-2003-4-9-r60

23. Huang DW, Sherman BT, Tan Q, Kir J, Liu D, Bryant D, et al. DAVID Bioinformatics Resources: expanded annotation database and novel algorithms to better extract biology from large gene lists. Nucleic Acids Res. 2007;35(Web Server issue):W169-75

24. Kanehisa M, Goto S. KEGG: Kyoto encyclopedia of genes and genomes. Nucleic Acids Res. 2000;28(1):27-30. https://doi.org/10.1093/nar/28.1.27.

25. Shannon P, Markiel A, Ozier O, Baliga NS, Wang JT, Ramage D, et al. Cytoscape: a software environment for integrated models of biomolecular interaction networks. Genome Res. 2003;13(11):2498-504. https://doi.org/1 $0.1101 / \mathrm{gr} .1239303$

26. Stark C, Breitkreutz BJ, Reguly T, Boucher L, Breitkreutz A, Tyers M. BioGRID: a general repository for interaction datasets. Nucleic Acids Res. 2006; 34(Database issue):D535-9. https://doi.org/10.1093/nar/gkj109.

27. Li T, Wernersson R, Hansen RB, Horn H, Mercer J, Slodkowicz G, et al. A scored human protein-protein interaction network to catalyze genomic interpretation. Nat Methods. 2017;14(1):61-4. https://doi.org/10.1038/ nmeth.4083.

28. Bader GD, Hogue CW. An automated method for finding molecular complexes in large protein interaction networks. BMC Bioinformatics. 2003; 4(1):2. https://doi.org/10.1186/1471-2105-4-2.

29. Scotto L, Narayan G, Nandula SV, Arias-Pulido H, Subramaniyam S, Schneider $A$, et al. Identification of copy number gain and overexpressed genes on chromosome arm 20q by an integrative genomic approach in cervical cancer: potential role in progression. Genes Chromosomes Cancer. 2008; 47(9):755-65. https://doi.org/10.1002/gcc.20577.

30. Zhai Y, Kuick R, Nan B, Ota I, Weiss SJ, Trimble CL, et al. Gene expression analysis of preinvasive and invasive cervical squamous cell carcinomas identifies HOXC10 as a key mediator of invasion. Cancer Res. 2007;67(21): 10163-72. https://doi.org/10.1158/0008-5472.CAN-07-2056.

31. Pyeon D, Newton MA, Lambert PF, den Boon JA, Sengupta S, Marsit CJ, et al. Fundamental differences in cell cycle deregulation in human papillomavirus-positive and human papillomavirus-negative head/neck and cervical cancers. Cancer Res. 2007;67(10):4605-19. https://doi.org/10.1158/ 0008-5472. CAN-06-3619.

32. Biewenga P, Buist MR, Moerland PD, Ver Loren Van Themaat E, Van Kampen $\mathrm{AH}$, Ten Kate FJ, et al. Gene expression in early stage cervical cancer. Gynecol Oncol. 2008;108(3):520-6. https://doi.org/10.1016/j.ygyno.2007.11. 024.

33. Nowinska K, Ciesielska U, Piotrowska A, Jablonska K, Partynska A, Paprocka $M$, et al. MCM5 expression is associated with the grade of malignancy and Ki-67 antigen in LSCC. Anticancer Res. 2019;39(5):2325-35. https://doi.org/1 0.21873 /anticanres. 13349 .

34. Laskey R. The Croonian lecture 2001 hunting the antisocial cancer cell: MCM proteins and their exploitation. Philos Trans R Soc Lond Ser B Biol Sci. 2005; 360(1458):1119-32. https://doi.org/10.1098/rstb.2005.1656.

35. Das M, Prasad SB, Yadav SS, Govardhan HB, Pandey LK, Singh S, et al. Over expression of minichromosome maintenance genes is clinically correlated to cervical carcinogenesis. PLoS One. 2013;8(7):e69607. https://doi.org/10.13 71/journal.pone.0069607.

36. Das M, Prasad SB, Yadav SS, Modi A, Singh S, Pradhan S, et al. HPV-typespecific response of cervical cancer cells to cisplatin after silencing replication licensing factor MCM4. Tumour Biol. 2015;36(12):9987-94. https:// doi.org/10.1007/s13277-015-3782-7.

37. Saritha VN, Veena VS, Jagathnath Krishna KM, Somanathan T, Sujathan K. Significance of DNA replication licensing proteins (MCM2, MCM5 and CDC6), p16 and p63 as markers of premalignant lesions of the uterine cervix: its usefulness to predict malignant potential. Asian Pac J Cancer Prev. 2018;19(1):141-8. https://doi.org/10.22034/APJCP.2018.19.1.141.

38. Kaur G, Balasubramaniam SD, Lee YJ, Balakrishnan V, Oon CE. Minichromosome maintenance complex (MCM) genes profiling and MCM2 protein expression in cervical Cancer development. Asian Pac J Cancer Prev. 2019;20(10):3043-9. https://doi.org/10.31557/APJCP.2019.20.10.3043.

\section{Publisher's Note}

Springer Nature remains neutral with regard to jurisdictional claims in published maps and institutional affiliations.

Ready to submit your research? Choose BMC and benefit from

- fast, convenient online submission

- thorough peer review by experienced researchers in your field

- rapid publication on acceptance

- support for research data, including large and complex data types

- gold Open Access which fosters wider collaboration and increased citations

- maximum visibility for your research: over $100 \mathrm{M}$ website views per year

At $\mathrm{BMC}$, research is always in progress.

Learn more biomedcentral.com/submissions 